\title{
Apendicite aguda pós colonoscopia: desafio diagnóstico e tratamento minimamente invasivo - relato de caso
}

\section{Case report - post-colonoscopy acute appendicitis: diagnostic challenge and minimally invasive treatment}

Marcelo de Paula loureiro, TCBC-PR; Eduardo Bonin² ${ }^{\text {; }}$ Camila Leiner $^{3}$; Shella Cristina Weigmann ${ }^{4}$; Aline Fontana ${ }^{5}$

\section{INTRODUÇAO}

A apendicite aguda após colonoscopia é uma complicação possível do método, tendo sido descrita apenas por 11 vezes na literatura de língua inglesa ${ }^{1}$. Representa um desafio diagnóstico, devendo ser lembrada em caso de dor abdominal em fossa ilíaca direita após o exame. Sua fisiopatologia envolve provavelmente a oclusão da luz apendicular, por fecalito empurrado pela pressão do gás insuflado². Até então esta inusitada situação ainda não havia sido tratada por laparoscopia.

\section{RELATO DO CASO}

Em Agosto de 2006, um paciente de 54 anos apresentou-se ao serviço de pronto socorro com dor abdominal de forte intensidade, iniciada quatro horas após dois exames endoscópicos (endoscopia digestiva alta e colonoscopia). Estes haviam sido solicitado como parte de protocolo de screening, estando portanto, o paciente assintomático antes do exame.

Na admissão, o paciente estava com dor abdominal difusa, mais pronunciada em flanco esquerdo, acompanhada de náuseas e vômitos, e hipotensão arterial $(80 \times 50 \mathrm{mmHg})$. Adotadas as medidas iniciais de controle da dor e pressão, foram feitos exames laboratoriais e radiológico. Este absolutamente normal, sem evidência de pneumoperitôneo ou distensão de alças. Já o hemograma mostrava discreta leucocitose de 12 mil com bastonetose de $7 \%$. Demais exames como amilase e enzimas hepáticas eram normais. O paciente foi internado e submetido, 12 horas após, a controle radiológico, ecografia abdominal e novos exames laboratoriais.

Novamente a rotina radiológica era normal, assim como a ecografia. A leucocitose apresentou discreta piora, agora com 13 mil e $11 \%$ de bastões. O exame abdominal, no entanto, não revelava sinais de localização, permanecendo inclusive o paciente com hábito intestinal e apetite normais.

A colonoscopia do dia anterior evidenciara diversos divertículos de cólon esquerdo, assim como um pólipo séssil, o qual havia sido ressecado. Além disto, uma lesão ulcerada de íleo terminal, biopsiada. O orifício apendicular, no momento do exame estava normal (Figura 1), porém um dos orifícios diverticulares apresentava sinais inflamatórios iniciais.

Tratamento para diverticulite aguda, com cefalosporinae metronidazol foi iniciado.

No dia seguinte, 36 horas após a admissão houve discreta piora da dor abdominal e do hemograma, com aumento da bastonetose para $20 \%$. O paciente permanecia todo o tempo sem febre, porém agora com dor mais localizada na fossa ilíaca direita. Foi realizada então uma tomografia abdominal.

Nesta evidenciou-se abscesso em FID e líquido na cavidade peritoneal (Figura 2).

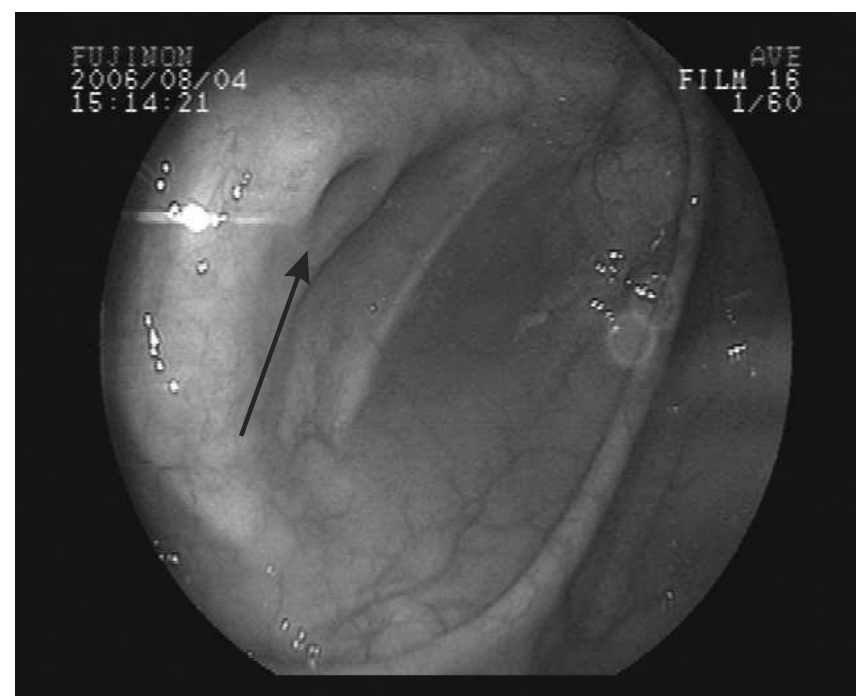

Figura 1 - Orifício apendicular íntegro durante o exame.

Trabalho realizado no Curso de Pós-Graduação da Universidade Positivo (Unicenp) e Hospital Santa Cruz de Curitiba - PR-BR.

1. Coordenador do Curso de Cirurgia Minimamente Invasiva do Instituto Jacques Perissat / Universidade Positivo e Membro da Retaguarda Cirúrgica do Hospital Santa Cruz de Curitiba- PR-BR; 2. Coordenador do Curso de Cirurgia Minimamente Invasiva do Instituto Jacques Perissat / Universidade Positivo - PR-BR; 3. Endoscopista do Serviço de Endoscopia do Hospital Santa Cruz de Curitiba - PR-BR; 4. Cirurgiã Geral; 5. Residente do Serviço de Cirurgia Plástica do Hospital Evangélico de Curitiba- PR-BR. 


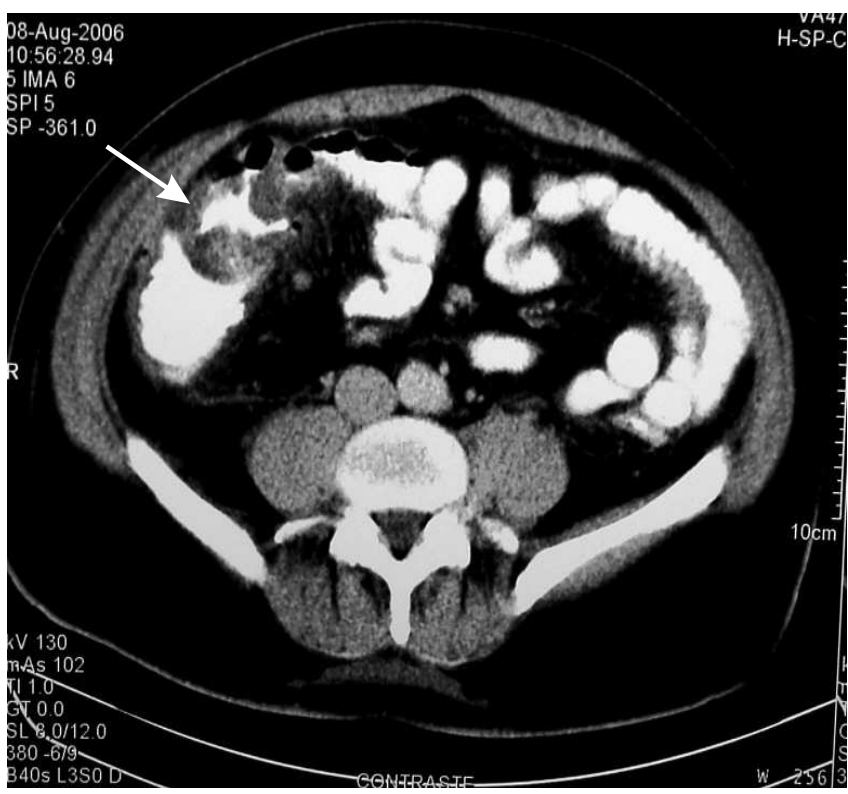

Figura 2 - Processo inflamatório apendicular. diagnóstica.

O paciente foi então submetido à laparoscopia

\section{TÉCNICA CIRÚRGICA}

A laparoscopia realizada cerca de 48 horas após o início dos sintomas seguiu o procedimento de costume do serviço. O paciente foi posicionado em decúbito dorsal, com ambos os braços ao longo do corpo e em posição de Tredelenburg, com inclinação de 30 graus. O cirurgião colocado ao lado esquerdo do paciente, assim como o primeiro auxiliar. O primeiro trocarte, utilizado para introdução da óptica foi colocado em posição supra- umbilical. Outros dois foram distribuídos em flanco esquerdo e fossa ilíaca esquerda.

Ao exame inicial da cavidade evidenciou-se grande quantidade de pus (cerca de um litro), o qual foi cuidadosamente aspirado e o abdomem limpo com cerca de cinco litros de solução salina a 0,9\%. O cólon esquerdo mobilizado não apresentava sinais inflamatórios nem tampouco havia aderência deste ao ceco-apêndice.

O plastrão apendicular foi desfeito e o apêndice cecal, com perfuração de sua base foi ressecado. Optou-se pela drenagem com dreno túbulo-laminar em fundo de saco e fossa ilíaca direita.

A evolução pós-operatória foi à esperada com alta no quarto dia, afebril, com hemograma e dieta nor- mais. Não foi investigada imunodeficiência. A histopatologia evidenciou displasia de baixo grau no pólipo ressecado da colonoscopia e apendicite aguda supurativa na peça cirúrgica.

\section{DISCUSSÃO}

A apendicite iniciada após colonoscopia representa um desafio diagnóstico, pois sua apresentação pode ser similar à complicações muito mais comuns deste exame, como perfuração e síndrome pós-polipectomia. Neste caso específico, o paciente poderia ter sua dor justificada tanto por uma perfuração, quanto pela ressecção de um pólipo, uma eventual diverticulite ou até mesmo pela pequena ulceração de íleo terminal. Além disto não possuía nenhum sinal inflamatório no óstio apendicular durante a colonoscopia.

Devido ao grande risco de uma apendicite não diagnosticada, é importante manter um alto grau de suspeita desta possível complicação. A tomografia deve ser o exame de eleição, para desvendar-se o mais cedo possível, a causa da dor ${ }^{3}$. Outras possíveis explicações para o desenvolvimento da apendicite após a colonoscopia seriam o preparo para o exame e o trauma do orifício apendicular com o aparelho ${ }^{4}$. A evolução desta apendicite com perfuração e peritonite difusa em 48 horas, pode estar relacionada à penetração de fecalito para o interior da luz apendicular e impactação do mesmo sob pressão. Tal fato poderia eventualmente propiciar aceleração no processo natural da própria apendicite.

Dentre os casos descritos, a proporção homem/ mulher foi de 10:1, a faixa etária de 54,4 anos e o aparecimento dos sintomas variou de 12 horas a cinco dias. Dez dos pacientes foram tratados por laparotomia, e um com antibióticoterapia exclusiva ${ }^{1}$. A laparoscopia é um excelente método diagnóstico complementar . Neste caso foi importante não só na elucidação definitiva do diagnóstico, mas sobretudo prestou-se ao tratamento da afecção, permitindo a ressecção do apêndice e a ampla limpeza da cavidade $^{5}$. Assim, mesmo em caso de peritonite difusa, o método auxilia na aspiração efetiva dos recessos abdominais e na lavagem contínua do abdômen durante o procedimento.

A apendicite aguda pós colonoscopia é uma situação que deve ser sempre lembrada em casos de dor abdominal após o exame. A tomografia e a laparoscopia exercem importante papel no diagnóstico e tratamento desta complicação.

\section{A B $\quad S \quad T$ R A C T}

We present a case of a 54-year-old man with abdominal pain four hours after colonoscopy and upper endoscopy. Since he had had a polipectomy and an ulcer was seen in the terminal ileum, the diagnosis of appendicitis was even more difficult. The authors discuss the rarity of this situation and the minimally invasive approach to treat appendicitis.

Key words: Appendicitis. Colonoscopy. Diagnosis. Case reports. 


\section{REFERENCIAS}

1. Izzedine $H$, Thauvin $H$, Maisel A, Bourry E, Deschamps A. Postcolonoscopy appendicitis: case report and review of the literature. Am J Gastroenterol 2005; 100(12):2815-7.

2. Petro $M$, Minocha A. Asymptomatic early acute appendicitis initiated and diagnosed during colonoscopy: a case report. World J Gastroenterol 2005; 11(34):5398-400.

3. Kapral C, Wewalka F, Kopf C, Aufreiter M, Lenz K. Acute appendicitis after colonoscopy: causality or coincidence ? Z Gastroenterol 2003; 41(10):999-1000.

4. Rosen MJ, Sands BE. Acute appendicitis following colonoscopy. J Clin Gastroenterol 2005; 39(1):78.

5. Sauerland S, Agresta F, Bergmaschi R, Borzellino G, Budzynski A, Champault $G$, et al. Laparoscopy for abdominal emergencies: evidence-based guidelines of the European Association for Endoscopic Surgery. Surg Endosc 2006; 20(1):14-29.
Recebido em 28/02/2007

Aceito para publicação em 01/04/2007

Conflito de interesse: nenhum

Fonte de financiamento: nenhuma

\section{Como citar este artigo:}

Loureiro MP, Bonin E, Leiner C, Weigmann SC, Fontana A. Apendicite aguda pós colonoscopia: desafio diagnóstico e tratamento minimamente invasivo - Relato de caso. Rev Col Bras Cir. [periódico na Internet] 2011; 38(5). Disponível em URL: http://www.scielo.br/rcbc

\section{Endereço para correspondência:}

Marcelo de Paula Loureiro

E-mail: mpailoureiro@gmail.com 